\title{
ICT SUPPORTED OCCUPATIONAL STRESS MANAGEMENT: THE VIEWS OF HR MANAGERS IN SRI LANKAN SOFTWARE COMPANIES
}

\author{
Manoja Weerasekara ${ }^{1,2}, \AA_{\text {Asa Smedberg }}^{2}$ and Hélène Sandmark ${ }^{3}$ \\ ${ }^{1}$ School of Computing, NSBM Green University Town, Pitipana, Homagama, Sri Lanka \\ ${ }^{2}$ The Department of Computer and Systems Sciences, Stockholm University, Kista, Sweden \\ ${ }^{3}$ Ramazzini Research, Lidingö, Sweden
}

\begin{abstract}
The software industry is considered to be a growing industry worldwide but with a high propensity to cause stress reactions among employees due to its demanding and technology-driven nature. As a human capital-intensive industry, too much of stress on employees can also create a negative impact on the quality of work. Thus, organizations take numerous initiatives at both individual and organizational levels to address this problem. One area of concern is the use of ICT supported occupational stress management interventions. In Sri Lanka, the dominant ICT occupation today is software engineer, and there is a national awareness of mental health issues due to occupational stress. Thus this study aims to investigate current practices used to frame employees' well-being inside software organizations in Sri Lanka, and to understand Sri Lankan software companies' viewpoints of using ICT supported occupational stress management interventions through the lens of human resource (HR) managers. Ten HR managers were interviewed covering eight software companies. Through thematic analysis, we identified three main themes and multiple subthemes. Results revealed various types of individual level and organizational level strategies, policies and practices implemented to create a healthy work setting for the employees. Findings also show that the HR managers had limited knowledge and experiences of ICT supported occupational stress management interventions. Nevertheless, they appreciated the immediate possible benefits of ICT interventions and demonstrated the willingness to adopt them in their organizations. Moreover, they revealed several functional requirements and feature sets they would like to see in such applications to better support their employees. Therefore, this study can possibly provide insights for researchers and practitioners who are to design and develop ICT supported interventions to manage occupational stress, to promote well-being and healthy organizations.
\end{abstract}

\section{KEYWORDS}

Well-Being, Digital Health Intervention, Occupational Stress Management, Sri Lanka, Software Industry, Human Resource Managers

\section{INTRODUCTION}

Occupational work is inherently stressful, and workplace stress is more on the rise than ever. According to the world health organization, stress has been dubbed as the "Health Epidemic of the 21st Century" (Fink, 2017). A recent global survey commissioned by The Regus Group, which included 1,000 corporations across 15 countries, also shows similar indications. The study found that six in ten workers in significant global economies experienced increased workplace stress, which is a significant rise compared to the previous two years (Esmond, no date). Occupational stress is a kind of stress associated with an individual's work environment and job conditions. The gap arises from the individual's knowledge, skills and capacity, and job demands causing stress reactions (Mustafa et al., 2015). However, occupational stress, or stress in general, is not uniformly negative. A desirable amount of stress motivates and encourages employees to learn and face challenging situations where an excessive amount of stress could cause negative impact on individuals and harm health and well-being of employees (Lazarus, 1993). Overcoming such stressful conditions mainly depends on the individual's capacity to adjust, and provision of adjustments in the work environment (Swanson and Fouad, 1999). Therefore, every organization promotes diversified approaches at both individual and organizational levels to reduce stress and to improve employee well-being. Though most all 
occupations are subjected to a series of stressors, comparatively, the software industry is considered a stressful workplace due to its fast-moving and demanding nature. This rapidly growing nature has created enormous opportunities and demands in the software industry. It often leads to a lot of health problems that come with continuous physical and mental stress (Padma et al., 2015). Thus, it is essential to explore the current context and future possibilities of stress management practices within a software house.

Sri Lanka is a multi-cultural and multi-ethnic country lying southeast of India with a population of 21.07 million in 2019. Recent statistics at the Mental Health Unit of Sri Lanka's Health Ministry mirror the global stress conditions; the statistics show that one in five public sector employees suffers from stress, and this has become a real issue that needs to be addressed at the workplace (Rosayro, 2017). However, as a country with a national awareness of mental health concerns due to occupational stress, Sri Lanka clarifies the vision for comprehensive mental health service for the citizens of Sri Lanka based on a community care model. It also promotes the treatment of mental illness holistically and discusses the role of a multidisciplinary team (Kathriarachchi, Seneviratne and Amarakoon, 2019). Currently, mental healthcare is provided through a combination of public, private and non-government services. Mental Health ATLAS 2017 Member State Profile of Sri Lanka recorded that there are only 1,480 mental healthcare professionals in both government and non-government sector, which gives $7.14 \%$ mental healthcare workers per 100,000 population. Because of the current shortage of mental healthcare human resources, there has been particular interest in introducing innovations to deal with the situation (Minas, Mendis and Hall, 2017). Along with the Government of Sri Lanka's (GOSL) visionary journey of transforming Sri Lanka into a "Knowledge Economy' the Information and Communication Technology (ICT) has a significant role to play in this journey. According to recent statistics published by the Information and Communication Technology Agency of Sri Lanka (ICTA), there is a dominance of software engineering followed by software quality assurance. In parallel to the GOSL vision, the SLASSCOM (Sri Lanka Association of Software and Service Companies - the apex body of Sri Lankan software and service companies) plan to create 200,000 direct jobs, enable 1,000 start-ups and to grow the industry revenue up to US $\$ 5$ billion by 2022 (ICTA, 2019). With the fast-paced industry and service environment, the competitive run to reach the next level requires employees to work long hours and to strive for continuous skill and capacity updates. This has resulted in lack of work-life balance and caused mental stress and mental disorders among workers in the software industry (Padma et al., 2015).

Thus, this study specifically aims to understand the Sri Lankan software companies' viewpoints of using ICT supported occupational stress management interventions through the lens of human resource (HR) managers working in Sri Lankan software companies. The outcome of this research could feed in as knowledge to the design and development of ICT tools for occupational stress management, to yield optimum efficacy levels.

\section{RESEARCH AIM AND OBJECTIVES}

As discussed in the introduction, this study aims to explore current HR and administrative practices of the Sri Lankan software companies to create a healthy work environment for the employees, and to investigate the companies' perceptions of the use of ICT for stress management interventions from the viewpoint of HR managers. The specific objectives of this research are: (1) to identify current HR management practices to enhance employee health and well-being inside a software company, (2) to learn about managers' experience of dealing with situations involving employee mental distress, and (3) to ascertain the managers' perspectives of the use of ICT supported occupational stress management interventions.

\section{LITERATURE REVIEW}

\subsection{Occupational Stress}

Occupational stress is associated with one's work environment or job conditions. Studies exploring the impact of work-related stress reactions show that it does not only impact on an individual level but also at the organizational and national level. At an individual level, high levels of stress can cause adverse cognitive difficulties (e.g. concentration problem, poor judgment, constant nervousness), behavioural issues 
(e.g. sleeping disorder, poor eating habits, use of drugs and alcohol), emotional problems (e.g. short temper, restlessness, impatient, depression) and physical problems (e.g. back and neck pains, heart problems, blood pressure, nausea, anxiety) (Burman and Goswami, 2018). It impacts on the organizational level with the increased absenteeism and presenteeism, as well as reduced commitment, motivation and satisfaction, along with a higher rate of staff turnover and intention to quit (Quick, 2013). Moreover, employees' stressful behaviours influence the company's overall competitiveness, productivity, and public image. At a broader level, stress-related disorders affect the economic and social environment of both individuals and organizations (Narváez, Tobar and López, 2014).

\subsection{Well-Being in the Workplace: Human Resource (HR) Management}

Employee health and well-being is considered the main focus area of HR management as it directly links with employee satisfaction and performance (Martin, Woods and Dawkins, 2018). The organizations consider employee health "not out of altruism, but as a key part of their business strategy" (Burke, 2014, p. 4). Within a rapidly changing economic and technological environment, a healthy workforce becomes a competitive advantage for organizations (Biron, Karanika-Murray and Cooper, 2012). The reduced performance due to sickness, absenteeism and presentism incur a substantial cost for employers. It affects the employee's innovative nature, communication and problem-solving skills, and it causes overall productivity loss (DeFrank, 2012). Thus the companies invest more and more to keep their workers present, healthy, and well (Black, 2009).

\subsection{Stress Management Interventions}

There are different job-related stress reduction strategies suggested in the literature to adjust individuals and work environments to create more desirable employee and work settings. Such adjustments are two-fold: 1. Individual adjustment strategies; 2. Environmental adjustment strategies (Black, J et al., 2019). Individual strategies include (1). Developing Self-Awareness- knowing the job requirement and prepare yourself to accept challenges, (2). Promoting Outside Interests- select suitable activities based on individual preferences, e.g. sports, music to take mindset off work, etc., (3). Finding a Personal or Unique Solution-individuals may identify suitable practices by their own in order to cope with stressful situations, e.g. guided imaginations, listen to music, etc., (4). Physical Exercise- engage in regular exercises to keep energy up, (5). Cognitive Perspective- framing the situations positively by distinguishing factors that are within as well as outside your control and influence, and (6). Leaving the organization- if an employee cannot adjust to the environment and the environment is also not changing in a positive way for the individual then the employee may investigate alternative employment opportunities (Black, J et al., 2019). The organizational level adjustment strategies are viewed as more desirable as they bring more control over the organization's employees and have more opportunity to contribute to creating a healthy work setting. Such organization strategies involve (1). Personnel Selection and Placement- pay more attention to the selection and placement process to recruit suitable job applicants for the job and the specific work environment, (2). Skills Training- provide numerous training programs to improve job-related skills, interpersonal skills, etc., (3). Job Redesign- job enrichment, job rotation, etc., to enhance job-person fit, (4). Company-Sponsored Counseling and Health Programs- provide awareness activities, programs and tools to cope with stress, (5). Increased Participation and Personal Control- allow employees greater participation and personal control in decisions affecting their work, (6). Work Group Cohesiveness- attempt to build workgroup cohesiveness through team building activities, and (7). Improved Communication- open communication channels, so that employees are more informed about what is happening in the organization (Black, J et al., 2019).

\subsection{ICT Supported Occupational Stress Interventions}

In the current context, digital health interventions are considered a growing phenomenon with promising outcomes. With the technological advancements and availability of digital resources, numerous initiatives have been explored to cater to human needs using eHealth and mHealth strategies. It is possible to carry them out at a larger scale, regardless of time, place or group of people (Cohen, Kessler, \& Gordon, 1995), and the user can access information in a quick, easy and confidential manner (McKenna \& Bargh, 2000). Looking at 
the ICT supported stress management interventions (ICTSMI), there are diversified approaches practiced using the web, mobile, sensor and hybrid platforms (Weerasekara and Smedberg, 2019). Such interventions provide support and interaction using various modalities; guided through human experts, guided through machines, guided and supported by peers, moderately guided, unguided, etc. (Weerasekara and Smedberg, 2019). It is not only the personalized and individualized care such interventions facilitate; they can also create a collaborative and interactive platform. These digital platforms allow getting connected with professional healthcare providers and people with similar health conditions. Such interactions enable the sharing of knowledge and experience (Brough, Dollard and Tuckey, 2014), providing a sense of belongingness and comfort leading to patient empowerment (LLUCH, 2011).

\subsection{Software Industry}

The growing needs of the organizations and industry have given birth to software houses (Rajeswari and Anantharaman, 2003). These software houses intend to fulfil the demands of their clients by using the latest technology and skills in the market (Nayak, 2014) and are considered as a human capital intensive industry with knowledge workers in a technology-intensive environment (Rajeswari and Anantharaman, 2003). Hence, the software industry is regarded as a stressful workplace due to its fast-moving and demanding nature. With the rapid technological advancements and changing nature of business requirements, software professionals need to abreast with them. Software engineers must confront different sorts of pressures, including (1). global pressures: market and rivalry, (2). technology pressures: rapid tech-advancements, and (3). local pressures: working hours and changing work culture due to its global software development nature (Amin et al., 2011).

\section{METHODOLOGY}

This study involves an exploratory and qualitative approach to understand and gain more knowledge on the current HR and administrative processes used to create and maintain healthy work settings for the employees. The first phase of the data collection process was designated to identify suitable companies for the investigation. To assure the uniformity of the selection of companies, only the SLASSCOM registered companies located in the Colombo district were selected. An online questionnaire was disseminated through email to the software and service companies on the list to gather demographic profiles of the companies. This mainly focused on identifying the company's core business area, operational status, number of employees, gender distribution support services, etc. The companies were selected based on the scale of the company in terms of the number of employees working in the organization. This scale was formed based on the enterprise classification defined by the World Bank for Sri Lankan companies; those with fewer than 49 employees were categorized as small; those with 50-99 employees were classified as medium-sized; and those with 100 employees or more as large companies (Ponnamperuma, 2000). Thus, the complete response list comprised of 11 small scale companies, five medium scale companies and 11 large scale companies. Based on the 27 responses received, a combined convenience and purposeful criterion sampling method was used to select respondents for the next phase. The selected eight companies consisted of three small scale companies, two medium scale companies and three large scale companies. The selection of companies was also based on the core business area (comprised of software development, quality assurance, networking, IT consultancy) and operation status (serves an only local market, serves both domestic and international market and serves only the global market). This purposive selection of participants provided an opportunity to receive different views and ideas from different perspectives to enrich the understanding of experience (Polkinghorne, 2005). Demographic data of the selected companies is detailed below in Table 1.

For the selected companies, an email was sent to the HR managers (in COMP2 there was no separate HR team, and thus the principal administration officer was contacted) requesting available date and time to have the interviews. Two email reminders and one text message were sent. Eight interviews were conducted with ten interviewees according to their convenience and preferences. Among them, four interviews were conducted as video conference meetings using either Skype or Zoom software applications. Three audio conferences were held using Skype, and one audio conversation took place through a mobile phone call. 
Table 1. Company and Respondent Demographics Data

\begin{tabular}{|c|c|c|c|c|c|c|c|c|}
\hline $\begin{array}{l}\text { Company } \\
\text { No. }\end{array}$ & $\begin{array}{l}\text { Core Business } \\
\text { Area* }\end{array}$ & $\begin{array}{l}\text { Operational } \\
\text { Status }\end{array}$ & $\begin{array}{l}\text { No. of } \\
\text { Employees }\end{array}$ & $\begin{array}{l}\text { Respo } \\
\text { ndent } \\
\text { No. }\end{array}$ & Gender & Age & $\begin{array}{l}\text { Education } \\
\text { Qualification }\end{array}$ & $\begin{array}{l}\text { Exper } \\
\text { ience } \\
\text { (no. of } \\
\text { years) }\end{array}$ \\
\hline COMP1 & $\begin{array}{l}\text { SWD, QAE, } \\
\text { NET }\end{array}$ & $\begin{array}{l}\text { Local and } \\
\text { international }\end{array}$ & 45 (Small) & HR1 & Female & 40 & $\begin{array}{l}\text { Postgraduate } \\
\text { Diploma in HR }\end{array}$ & 8 \\
\hline \multirow[t]{2}{*}{ COMP2 } & \multirow[t]{2}{*}{ SWD, QAE } & \multirow[t]{2}{*}{ Local } & \multirow{2}{*}{$\begin{array}{l}19 \\
\text { (Small) }\end{array}$} & HR2 & Male & 31 & MBA & 6 \\
\hline & & & & HR3 & Male & 33 & MBA & 6 \\
\hline COMP3 & $\begin{array}{l}\text { SWD, QAE, } \\
\text { ITC }\end{array}$ & International & $\begin{array}{l}22 \\
\text { (Small) }\end{array}$ & HR4 & Female & 25 & BSc in IT & 2 \\
\hline COMP4 & SWD & International & $\begin{array}{l}55 \\
\text { (Medium) }\end{array}$ & HR5 & Female & 33 & MBA & 9 \\
\hline COMP5 & SWD & $\begin{array}{l}\text { Local and } \\
\text { international }\end{array}$ & $\begin{array}{l}90 \\
\text { (Medium) }\end{array}$ & HR6 & Female & 34 & MBA & 8 \\
\hline COMP6 & SWD & International & $\begin{array}{l}900+ \\
\text { (Large) }\end{array}$ & HR7 & Male & 43 & MBA & 17 \\
\hline \multirow[t]{2}{*}{ COMP7 } & \multirow[t]{2}{*}{ SWD } & \multirow{2}{*}{$\begin{array}{l}\text { Local and } \\
\text { international }\end{array}$} & \multirow{2}{*}{$\begin{array}{l}200 \\
\text { (Large) }\end{array}$} & HR8 & Female & 28 & MBA & 4 \\
\hline & & & & HR9 & Male & 30 & $\begin{array}{l}\text { Postgraduate } \\
\text { Diploma in HR }\end{array}$ & 6 \\
\hline COMP8 & $\begin{array}{l}\text { SWD, QAE, } \\
\text { NET, ITC }\end{array}$ & International & $\begin{array}{l}200+ \\
\text { (Large) }\end{array}$ & HR10 & Female & 31 & MBA & 6 \\
\hline
\end{tabular}

*SWD: Software Development, QAE: QA Engineering, NET: Networking, ITC: IT Consultancy

Since this study was carried out during the outbreak of the coronavirus disease 2019 (COVID-19), data collection was conducted online. Thus, several initiatives were taken to conduct an ethically sound investigation to mitigate possible ethical challenges of internet-based research. Data were collected through semi-structured interviews, which allowed the researcher to focus on specific themes while adhering to the conversational style of interviewing (Polkinghorne, 2005). The interviews were conducted using English or in the participant's native language (Sinhala), and each meeting took $15-35 \mathrm{~min}$. The interview guide focused on background data and current HR practices, support services, stress management programs, the interviewee's awareness and experience of ICT in stress management practices, and perception of ICT supported stress management interventions. The interviews were recorded digitally upon receiving verbal consent from the participants. All the interviews were transcribed to written text for analysis purpose. The verbatim transcribed interviews were analyzed using inductive thematic analysis. The inductive thematic analysis supports identifying, analyzing, and reporting patterns from responses or data, which allows the researcher to organize and describe the data in detail (Braun and Clarke, 2006).

\section{RESULTS}

As a result of the inductive thematic analysis of the participants' responses, three major themes emerged. In this section, the themes and their subthemes (see Table 2) are explained in detail. The descriptions are supported with direct quotations from the participants.

Table 2. Summary of Themes and Subthemes

\begin{tabular}{|c|c|c|c|}
\hline Themes & Subthemes & $\begin{aligned} \text { Categories } \\
\end{aligned}$ & Remark \\
\hline \multirow{3}{*}{$\begin{array}{l}\text { Healthy } \\
\text { Workplace } \\
\text { and Happy } \\
\text { Employee }\end{array}$} & $\begin{array}{l}\text { Workplace } \\
\text { ergonomics }\end{array}$ & Seating arrangement, Floor plan & \multirow{3}{*}{$\begin{array}{l}\text { Identifies } \\
\text { different } \\
\text { organizational } \\
\text { strategies placed } \\
\text { to create a } \\
\text { healthy work } \\
\text { environment }\end{array}$} \\
\hline & $\begin{array}{l}\text { Availability of } \\
\text { support services }\end{array}$ & $\begin{array}{l}\text { Insurance schemes, Leave facilities, Transport, Food and } \\
\text { beverages, Daycare }\end{array}$ & \\
\hline & Workplace strategies & $\begin{array}{l}\text { Company structure and environment, Cohesive Team and } \\
\text { Team Work, Recruitment \& Job Design, Training and } \\
\text { Evaluations, Inculcating outside interests }\end{array}$ & \\
\hline
\end{tabular}




\begin{tabular}{|c|c|c|c|}
\hline \multirow{3}{*}{$\begin{array}{l}\text { The HR } \\
\text { Role and } \\
\text { Stressed } \\
\text { Employee }\end{array}$} & $\begin{array}{l}\text { Awareness and } \\
\text { acceptance }\end{array}$ & $\begin{array}{l}\text { Stressful periods, Work planning, support and guide, } \\
\text { Human skills development training }\end{array}$ & \multirow{3}{*}{$\begin{array}{l}\text { Explores the } \\
\text { manager's } \\
\text { experience of } \\
\text { interacting with } \\
\text { stressed } \\
\text { employees }\end{array}$} \\
\hline & Communication & Channels, Trust, Openness, Availability & \\
\hline & Challenges & $\begin{array}{l}\text { Age barrier, Stigma, Stressors: family or work } \\
\text { Early identification, size of the company }\end{array}$ & \\
\hline \multirow{3}{*}{$\begin{array}{l}\text { ICTSMI: } \\
\text { Accept or } \\
\text { Reject }\end{array}$} & Positive attitudes & Awareness, Willingness, Acceptance & \multirow{3}{*}{$\begin{array}{l}\text { Discusses } \\
\text { managers' } \\
\text { perspectives on } \\
\text { ICT supported } \\
\text { stress- } \\
\text { management } \\
\text { intervention }\end{array}$} \\
\hline & Doubtful attitudes & $\begin{array}{l}\text { Lack of awareness and experience, Negative experience, } \\
\text { human to machine replacement }\end{array}$ & \\
\hline & Feature requirements & $\begin{array}{l}\text { Conversational agent, Early detection, Alerts, Differentiate } \\
\text { workplace stressors and family matter, Emoji usage }\end{array}$ & \\
\hline
\end{tabular}

\subsection{Theme 01: Healthy Workplace and Happy Employee}

The theme "Healthy workplace and happy employee" elaborates the various types of strategies implemented by the organizations to assure the employee well-being. This includes the setup of the physical environment, various support services and facilities provided, and company level strategies implemented in the organizations to create a healthier work setting for its employees.

\subsubsection{Workplace Ergonomics}

This subtheme discusses the various approaches taken to set up a healthy physical environment. The participants strongly believed, since employees spend a lot of time inside the building, that the physical environment influences employee well-being and has direct impact on the employees' work performance and productivity. Therefore, they had taken different measures to create a favourable layout of the office space. This included the work cabin arrangements, workspace design with numerous physical facilities including pantry, lobby areas, private meeting rooms, prayer rooms, sick rooms, etc. Such arrangements became evident through:

HR1: "This place is small and cosy. Currently, our administration is trying to renovate the environment to make this place more relaxing."

HR5: "Our office space is designed to provide a convenient and friendly atmosphere for our employees."

HR7: "There are pool tables and relaxation areas, the pantry area is also quite large so they can use it to gather and relax, the sick room is there, if you feel uncomfortable you can go there to relax, we have prayer rooms separately, conference rooms (...)."

\subsubsection{Availability of Support Services}

The second subtheme explores the different benefit packages offered by the companies above the salaries and wages to their employees to make them benefited and satisfied. These employee benefits packages include health insurance, vacation and holiday facilities, transport facilities, a daycare facility for children, free food and beverages, etc.

HR10: "We offer hotel vouchers so they can go on vacation with their families utilizing their annual leaves."

HR4: "If they stay late at night, we reimburse transport and food expenses. All the employees have a medical insurance policy as well."

HR7: "Lunch is provided, the medical facility is there, the daycare facility is there, more than $50 \%$ is paid by the company (...)."

HR6: "We have a health insurance policy for all the employees, we provide meals and transport facilities when they work late nights."

\subsubsection{Workplace Strategies}

The final subtheme of Theme 01 consists of explicit and implicit strategies created, or evolved, and maintained in an organization to make its culture healthier for its employees. There are five main categories identified in this subtheme: Company structure and environment, Cohesive Team and Teamwork, Recruitment \& Job Design, Training and Evaluations, and Inculcating outside interests. 
The companies claimed to follow a flat structure and to have a friendly atmosphere inside the organization. They followed the open-door policy, to have the employees feel easy and welcomed to meet any other employee or manager without any prior appointment.

HR8: "Here we practice open-door policy, any employee can visit any employee's workspace without getting any prior approval. Even this is the same with the top management."

HR10: "We practice open-door policy, even for the CEO or chairpersons there's no separate room, and everyone is sitting on the same floor, if you want to talk to the CEO you can go directly and talk."

HR3: "We have no hierarchy; we have a flat structure here."

They also provided flexible working hours and working from home facility to let the employees feel more relaxed at work.

HR10: "We provide working from home facilities, so they don't have travelling problems."

HR1: "We follow flexi hours. Normal working hours are from 8.30-5.30 pm, but normally no one comes at 8.30 am."

A shared practice identified in all the companies was the "teamwork." All the companies formed their workflows into 'team' mode. The team was given a task, and members worked as a team to reach the set targets. The team was managed by a team lead/s who took on a supervisor role. The respondents figured that the team members were more open to the supervisor and their peers, and that such structure tended to alleviate communication regarding work as well as obstacles they were facing.

HR2: "We practice teamwork, employees recognize (company name) as a family; it's not an image that we created but created by themselves and maintained by themselves."

HR7: "We try to maintain good communication, collaboration and a kind of bonding with the manager and the member."

The "Buddy" concept had been introduced in some companies, along with the team concept. The buddy was described as a peer working in the same project and assigned to co-work with new employees. The buddy was responsible for and supported the work assignments, and this person helped others to adjust to the work setting and work culture.

HR9: "We assign a buddy who may not be a supervisor. Buddy is like a senior fellow who will help him to understand the context. We provide a budget for the buddy and the newcomer to go for lunch together (buddy lunch out)"

Companies also provided team allowances to let teams go out for team outings. This was intended to strengthen the teams and to avoid conflicts and create a more friendly environment.

HR10:" We provide leisure allowance for the teams where they can go outing as a team."

The participants explained that, while using internal strategies to create the cohesive teams and well-performing employees, they also strived to identify the right candidates for job positions.

HR3: "When it comes to recruitment, our interviews are a little bit tough because we need to select the best ones. We recruit only people who can match the level of the existing ones. (...) We look at whether they have the potential to learn from others, if we think they can learn, yes, we recruit them."

HR10: "We hire them based on their talent whenever there's a vacancy in a team, we recruit the right talent."

Next, the HR managers explained that the companies paid attention to training and evaluation process. They revealed that they tried to have a transparent evaluation process throughout the year, to let employees become aware of the areas that they should improve.

HR4: "We have surveys from time to time to check employee's satisfaction and happiness."

HR7: "We try to have one-to-one meetings, and we strive to give feedback, both good and bad, continuously, so they are not surprised at the annual evaluations because they know what's going on and they feel comfortable in their work positions."

It was also explained that the companies provided various workshops and training to improve the required knowledge and skills of their employees.

HR4: "We have technical training workshops for employees to improve their knowledge and skills. We have frequent knowledge sharing sessions."

Inculcating outside interest is another aspect the addressed companies focused on. Besides the work-related activities, companies introduced various extracurricular activities; annual trips, team outings, sports, musical events, etc., for their employees to increase work-life balance.

HR1: "We arrange different activities. Once a month we arrange a movie out, every Tuesday and Thursday evening we go for badminton." 
HR8: "Very recently, we had Valentine's day party, which they enjoyed a lot. We also have carom tournaments, movie nights and paduru party (musical events) to change their work environments and to make them enjoy and relax."

\subsection{Theme 02: The HR Role and Stressed Employee}

The second theme discusses the managers' experience with stressed employees. This will give details on their awareness of stressful conditions within the work setting, how they were managing and dealing with such situations and employees, and the perceived challenges.

\subsubsection{Awareness and Acceptance}

It was evident from the interviews that the managers, particularly in large and medium scale organizations, had noticed and worked with stressed employees. In such cases, they positively accepted and attempted to take necessary actions to reduce such stressful situations and to improve work-life balance.

HR10: "When there's delivery/deployment, the stress level goes high because they have to put their full strength, work in full time, work overnight, deal with customers and managers. Those days their stress level is high, and that we know. That is why we create a space for them to relax, provide flexible working hours and flexibility in everything (...)."

HR1: "There are few specialized resources for those we have no replacements, so they are bit stressed sometimes. But as a team, they try to manage their workload."

HR5: "Yes, we have recognized employees who suffered from stress, and we are aware that there are periods which are stressful for our employees."

However, participants from two of the small scale organizations believed that the employees were not stressed nor that the company environment needed to take any special stress management measures.

HR2: "Here they are not stressed. In our collaborative work environment they support each other."

HR4: "I believe our culture is very positive and friendly and not that stressful."

\subsubsection{Communication}

All the participants revealed that effective communication is the tool they used to reach their employees and to create a culture for them to bring up their problems. They tried to make themselves available and open to any matter. They believed trust and friendliness geared towards more open discussions.

HR8: "Sometimes we are busy, but when an employee reaches us with a grievance or problem or just for a chat, we make sure that we are available for them."

HR3: "We use a communication channel called slack. So, it helps to have improved efficient communication among employees."

HR6: "We are very close to our employees, so they tend to raise any concerns they have."

\subsubsection{Challenges}

HR managers said that they had observed age, stigma and company size as main problems averting the communication between HR and employees. They emphasized that with a young HR panel in the same age as their employees, they tended to communicate all the problems more openly, but this could change with more aged HR personnel.

HR2: "I think age matters in this. We are also not that aged, and employees are also the same, so they all cooperate very well. If there is an age gap, they might not easily open up like this. They come and talk to us if there's a problem at home still they talk about it if they want a salary increment, they talk to us, not as a dispute but just as a friendly talk."

HR1: "What I have noticed is that some employees if they have a problem, they are not communicating with HR. They just communicate when they are about to leave the organization."

HR9: "We know that sometimes with different attitudes, some employees are not willing to open up and communicate their problems."

Size of the company also acted as a challenge; in small scale organization, they explained that they could provide one-to-one attention, but in large organizations, it was regarded challenging to manage early detection of stress symptoms and stressors. 
HR3: "If one person is getting late to work for a couple of days or leave work early frequently or if he's not in a good mood at a meeting we figure out that there's a problem. Since team size is small, we can manage and give one-to-one attention, because of this practice, many issues are resolved easily at an early stage."

\subsection{Theme 03: ICTSMI: Accept or Reject}

The final theme "ICTSMI: accept or reject" addresses the company perspectives on ICTSMI through the lens of HR managers. This theme comprises of three subthemes: "Positive attitudes", "Doubtful attitudes" and "Feature requirements".

\subsubsection{Positive Attitudes}

Participants elaborated on their awareness of ICTSMI. Though some managers had only minimal awareness and experience with ICTSMI, still they perceived ICT supported interventions as an interactive and efficient means to identify and manage stress among employees.

HR4: "Yes, I think it's good to have a platform or system that we could use to support employees who are suffering from stress (...). “

HR10: "Yes, we believe that ICT supported interventions could support our employees to manage their stress levels. As an organization, we are happy to use them and promote them among our employees.

\subsubsection{Doubtful Attitudes}

Though the positive perceptions outweighed the doubtful opinions, some managers did not have confidence in ICTSMI due to negative experiences, lack of awareness, and knowledge and expertise. Participants appreciated the value of face-to-face communication in the counselling process and doubted that machine-based communication settings could replace the effectiveness of the human conversation.

HR10: "When it comes to stress management, rather letting people read, listen and watch videos, I think stress management should be related to discussions, conversations, the sort of things involving experts."

HR7: "I have one experience where he was stressed, and he had a family issue, and he was trying to use different applications available online, and he failed, then he came to us and talked about his problem. I know that there are useful applications, but when it comes to stress management, I think counselling is a must."

HR5: "I haven't used or are aware of such interventions. If they could offer the required functions, we may use them in our organization."

\subsubsection{Feature Requirements}

Conversations with the HR managers revealed several feature requirements that they expected from ICTSMI. These mainly included creating an effective platform for communication, stress level and stressors identification and enhancing employee awareness on stress management.

HR9: "I think there should be an initial screening process where individuals could assess themselves for stress levels so they could decide when to seek support."

HR4: "I prefer to have a platform that employees can use to communicate with us directly."

HR1: "It'll be great if we can have a system to get to know about how they feel and if they can use it to communicate with the HR directly. Especially if we can recognize whether it's a problem related to their personal life or work life."

HR2: "If we can have a system feature to express their feelings using emojis or images, then they could easily express their feelings rather than typing."

\section{DISCUSSION}

The general objective of this study was to explore the software company perspective of ICT supported interventions through the views of HR managers. The three main themes and nine subthemes extracted from the interviews provided valuable insights into the current strategies implemented in software organizations to create a healthier work setting for their employees. The findings did highlight not only managers' positive 
perception of ICTSMI but also doubtful thoughts which might hinder the possible use or implementation of ICTSMI within an organization.

According to literature, reducing stress and improving employee well-being is facilitated via diversified approaches at both individual and organizational level (DeFrank \& Cooper, 1987). The individual level interventions target individual employees to develop their skills to manage stress. In contrast, the corporate level approaches focus on the systematic changes to organizational practices that either target all the employees or a specific group of employees (Holman, Johnson and O' Connor, 2018). Considering the focus of the stress management interventions, they could be categorized as primary, secondary and tertiary (DeFrank and Cooper, 1987). The primary interventions focus on preventing stress by eliminating stressors and enhancing cases of well-being. Secondary interventions aim to reduce the severity of the stress and to avoid the level of stress becoming problematic. Tertiary interventions target rehabilitation and maximizing the functionality of employees who are already suffering from mental ill-health. Accordingly, the current findings also show similar mechanisms and strategies adopted in software companies to assure well-being of the employees.

Healthy physical setup of the organization, flat hierarchy and the open-door policy concept mentioned in the interviews are valuable to create a friendly atmosphere within the organization supporting more open conversations among employees and administration (Black, J et al., 2019). Regardless of the size of the company, these types of structures were present in all the eight companies. Another factor revealed by all the companies and mostly highlighted by the respondents in the large scale companies was how they arranged the physical environment. It was noted that the large companies strived to setup more convenient physical work settings and make a more cohesive environment to bridge distance and provide more opportunities to work closely with colleagues (Aries, Veitch and Newsham, 2010). This type of installation aims to mirror the one-to-one attention provided by the small and medium companies to their employees. Literature also shows that characteristics of the physical office environment can have a significant impact on behaviour, perceptions and productivity of employees (Kamarulzaman et al., 2011).

All the organizations offered different types of benefits packages to their employees. It was shown that the large scale software companies in the study had rich and more established benefit schemes over the small and medium scale companies. Benefits schemes, including health insurance, annual leaves, daycare facility, free meals transport services, etc., could provide a sense of comfort and help to attract and retain employees (Bernhard, 2018), and could support to alleviate stressful conditions which are more common in larger scale companies (Dekker and Barling, 1995). Such schemes could be considered as a way of responding to employee stress issues and labelled as an employee benefit for employer's benefit (Wheeler and Lyon, 1992).

It is noteworthy to mention that flexible working hours and working from home facility provided by the software companies act as a family-friendly policy which supports employees to balance their work-life (Shagvaliyeva and Yazdanifard, 2014).

In all the interviews, it was explained how the companies facilitated a team-based working culture where peers could help each other. This kind of initiative is in line with a study by Peterson et al. (2008), suggesting that peer-support groups could be a useful and comparatively inexpensive tool in alleviating work-related stress and burnout. However, organizations must pay careful attention to such implementation as the same initiatives might create unintended pressure on trained employees (Agarwal, Brooks and Greenberg, 2019). Secondary-individual strategies like health and relaxation, promoting programs investing in company trips, teams outings, sports activities, and parties provide employees with opportunities to engage in stress-reducing activities (Kondo, Jacoby and South, 2018). Acknowledging different personalities is important still since direct or indirect forceful participation or availability of preferred options might hinder the involvement and effectiveness of such initiatives (Edwards, 2012).

The selection and assessment procedures implemented inside an organization are considered as a primary-individual level strategy which ensures the selection of a candidate who has the right set of skills and attitudes to manage the demand from the job (Pulakos, 2005). However, this might implicitly force the employees to be in a continuous struggle to achieve their best to secure their job positions, imposing stressful mentality on them (World Health Organization, 2002).

Results revealed that the HR managers in the small scale software companies believed that their work settings were stress-free environments. However, over expectations and misbeliefs about the current situation might impact negatively on the employees (World Health Organization, 2002). Some employees might feel that if they suffer from stress in such a situation, company culture will characterize them as personal mismatches. Thus, they might remain unobserved and unspoken regarding their stressful conditions. 
Therefore it is essential to identify a more personalized and customized solution to manage employee stress within an organization.

Despite the HR managers' awareness and willingness to accept ICTSMI, the study also revealed challenges and drawbacks of using ICT in occupational stress management practices. They expressed how they doubted the possibility of replacing the human with a machine in a stress counselling situation. Such doubtful attitudes were based on negative experiences and also limited knowledge of ICTSMI. Since the successful implementation of ICTSMI in an organization tends to accelerate by the positive perception of managers (Ariani, Koesoema and Soegijoko, 2017), it is essential to take necessary measures to increase their awareness and positive experience of ICTSMI.

\section{CONCLUSION}

Over time, the research literature and experience with ICTSMIs within organizations will grow, and more consensus will be reached regarding which ICT interventions have a greater benefit to employees who need stress management. Thus, the results of this study could contribute to the already existing knowledge base, through increased understanding of current organizational practices and strategies implemented to create healthy workplaces and of the possibilities and challenges related to using ICTSMI in a technology-intensive work setting. It also elaborates features suggested by HR managers that, integrated into ICTSMIs, could help to better target stress-related problems at work. The findings could contribute to future design and development of ICT tools for stress management not only in the Sri Lankan context but also at the international level. However, it is also relevant to investigate employees' experiences and views on ICT supported stress management in future studies.

\section{REFERENCES}

Agarwal, B., Brooks, S. K. and Greenberg, N. (2019) 'The Role of Peer Support in Managing Occupational Stress: A Qualitative Study of the Sustaining Resilience at Work Intervention', Workplace Health \& Safety. SAGE Publications Inc, 68(2), pp. 57-64. doi: 10.1177/2165079919873934.

Amin, A. et al. (2011) 'Occupational stress, knowledge sharing and GSD communication barriers as predictors of software engineer's creativity', IEEE International Conference on Industrial Engineering and Engineering Management, pp. 394-398. doi: 10.1109/IEEM.2011.6117946.

Ariani, A., Koesoema, A. P. and Soegijoko, S. (2017) Innovative Healthcare Applications of ICT for Developing Countries. doi: 10.1007/978-3-319-55774-8.

Aries, M. B. C., Veitch, J. A. and Newsham, G. R. (2010) 'Windows, view, and office characteristics predict physical and psychological discomfort', Journal of Environmental Psychology, 30(4), pp. 533-541.

Bernhard, K. (2018) To attract and retain key employees, offer benefits that they value. Available at: https://www.bizjournals.com/bizjournals/news/2018/09/11/to-attract-and-retain-key-employees-offer-benefits.html (Accessed: 15 May 2020).

Biron, C., Karanika-Murray, M. and Cooper, C. L. (2012) 'Organizational interventions for stress and well-being - An overview', Improving Organizational Interventions for Stress and Well-Being: Addressing Process and Context, (2012), pp. 1-18. doi: 10.4324/9780203723494.

Black, J, S. et al. (2019) Organizational Behavior. Texas: OpenStax. Available at: https://openstax.org/details/books/organizational-behavior.

Black, C. (2009) 'Working for a healthier tomorrow', Occupational and Environmental Medicine, 66(1), pp. 1-2.

Braun, V. and Clarke, V. (2006) 'Using thematic analysis in psychology', Qualitative Research in Psychology, 3(2), pp. 77-101. doi: 10.1191/1478088706qp063oa.

Brough, P., Dollard, M. F. and Tuckey, M. R. (2014) 'Theory and methods to prevent and manage occupational stress: Innovations from around the globe', International Journal of Stress Management, 21(1), pp. 1-6. doi: $10.1037 / \mathrm{a} 0035903$.

Burke, R. J. (2014) 'Corporate wellness programs: an overview', Corporate Wellness Programs, pp. 3-27.

Burman, R. and Goswami, T. G. (2018) 'A Systematic Literature Review of Work Stress', International Journal of Management Studies, V(3(9)), p. 112. doi: 10.18843/ijms/v5i3(9)/15.

DeFrank, R. S. (2012) 'Teaching a Comprehensive Course on Stress and Work', Journal of Management Education, 36(2), pp. 143-165. doi: 10.1177/1052562911427834. 
DeFrank, R. S. and Cooper, C. L. (1987) 'Worksite Stress Management Interventions':, Journal of Managerial Psychology. MCB UP Ltd, 2(1), pp. 4-10. doi: 10.1108/eb043385.

Dekker, I. and Barling, J. (1995) 'Workforce Size and Work-Related Role Stress', Work \& Stress, 9, pp. 45-54.

Edwards, J. (2012) 'Understanding the predictors of participation and the barriers to employee involvement in workplace health promotion programmes', pp. $1-81$ Available https://mro.massey.ac.nz/bitstream/handle/10179/4078/02_whole.pdf.

Esmond, J. (no date) STRESS FACTS. Available at: http://www.gostress.com/stress-facts/ (Accessed: 17-09-2019).

Fink, G. (2017) 'Stress: Concepts, Definition and History', Reference Module in Neuroscience and Biobehavioral Psychology, (January), pp. 0-9. doi: 10.1016/b978-0-12-809324-5.02208-2.

Holman, D., Johnson, S. and O' Connor, E. (2018) 'Stress Management Interventions: Improving Subjective Psychological Well-Being in the Workplace', Handbook of well-being, pp. 1-13. doi: nobascholar.com.

ICTA (2019) NATIONAL IT - BPM WORKFORCE SURVEY 2019.

Kamarulzaman, N. et al. (2011) 'An overview of the influence of physical office environments towards employees', Procedia Engineering, 20, pp. 262-268. doi: 10.1016/j.proeng.2011.11.164.

Kathriarachchi, S., Seneviratne, Vl. and Amarakoon, L. (2019) 'Development of mental health care in Sri Lanka: Lessons learned', Taiwanese Journal of Psychiatry, 33(2), p. 55. doi: 10.4103/tpsy.tpsy_15_19.

Kondo, M. C., Jacoby, S. F. and South, E. C. (2018) 'Does spending time outdoors reduce stress? A review of real-time stress response to outdoor environments', Health and Place. Elsevier Ltd, 51(March), pp. 136-150.

Lazarus, R. S. (1993) 'FROM PSYCHOLOGICAL STRESS TO THE EMOTIONS " A History of Changing Outlooks', Annual Review of Psychology, 44, pp. 1-21.

LLUCH, M. (2011) 'Empowering Patients through ICT Organisational Impact on Healthcare Systems in England and Scotland', COMMUNICATIONS \& STRATEGIES, 83(3), pp. 37-58.

Martin, A., Woods, M. and Dawkins, S. (2018) 'How managers experience situations involving employee mental ill-health', International Journal of Workplace Health Management, 11(6), pp. 442-463.

Minas, H., Mendis, J. and Hall, T. (2017) 'Mental Health System Development in Sri Lanka'.

Mustafa, M. et al. (2015) 'Causes and Prevention of Occupational Stress', IOSR Journal of Dental and Medical Sciences, 14(November 2015), pp. 98--104. doi: 10.9790/0853-1411898104.

Narváez, S., Tobar, Á. M. and López, D. M. (2014) 'Systematic review of interventions supported by ICT for the prevention treatment of occupational stress', in Studies in Health Technology and Informatics, pp. 71-80.

Nayak, R. D. (2014) 'Anxiety and Mental Health of Software Professionals and Mechanical Professionals', International Journal of Humanities and Social Science Invention, 3(2), pp. 52-56.

Padma, V. et al. (2015) 'Health problems and stress in Information Technology and Business Process Outsourcing employees', Journal of Pharmacy \& Bioallied Sciences. India, pp. S9-S13. doi: 10.4103/0975-7406.155764.

Polkinghorne, D. E. (2005) 'Language and meaning: Data collection in qualitative research.', Journal of Counseling Psychology. American Psychological Association, 52(2), pp. 137-145. doi: 10.1037/0022-0167.52.2.137.

Ponnamperuma, E. N. (2000) 'SMEs in Competitive Markets, Country Paper', Asian ProductivityOrganization Tokyo, pp. 295-313.

Pulakos, E. D. (2005) 'Selection Assessment Methods: A guide to implementing formal assessments to build a high-quality workforce', SHRM Foundation, pp. 1-54. Available at: https://www.shrm.org/hr-today/trends-andforecasting/special-reports-and-expert-views/documents/selection-assessment-methods.pdf.

Quick, J. C. (2013) Preventive stress management in organizations. 2nd ed. Washington, District of Columbia: American Psychological Association.

Rajeswari, K. S. and Anantharaman, R. N. (2003) 'Development of an Instrument to Measure Stress Among Software Professionals: Factor Analytic Study', Proceedings of the ACM SIGMIS CPR Conference, pp. 34-43.

Rosayro, G. de (2017) 'Society must help in battle with depression and anxiety', dailynews, 9 October. Available at: http://www.dailynews.lk/2017/10/09/features/130539/society-must-help-battle-depression-and-anxiety?page=29.

Shagvaliyeva, S. and Yazdanifard, R. (2014) 'Impact of Flexible Working Hours on Work-Life Balance', American Journal of Industrial and Business Management, 04(01), pp. 20-23. doi: 10.4236/ajibm.2014.41004.

Swanson, J. L. and Fouad, N. A. (1999) 'Applying theories of person-environment fit to the transition from school to work.', The Career Development Quarterly. US: American Counseling Assn, pp. 337-347.

Weerasekara, M. and Smedberg, A. (2019) 'Design practices and implications in information and communication technology supported occupational stress management interventions', 2019 International Conference on Advanced Computer Science and Information Systems, ICACSIS 2019, pp. 285-294. doi: 10.1109/ICACSIS47736.2019.8979813.

Wheeler, S. and Lyon, D. (1992) 'Employee Benefits for the Employer's Benefit: How Companies Respond to Employee Stress', Personnel review. Bradford, England : doi: 10.1108/00483489210021053.

World Health Organization (2002) Mental health and work: Impact, issues and good practices. 